\title{
Meta-analysis to estimate the load of Leptospira excreted in urine: beyond rats as important sources of transmission in low-income rural communities
}

\author{
Veronica Barragan ${ }^{1,2,3}$, Nathan Nieto ${ }^{2}$, Paul Keim ${ }^{1,2}$ and Talima Pearson ${ }^{1,2^{*}}$
}

\begin{abstract}
Background: Leptospirosis is a major zoonotic disease with widespread distribution and a large impact on human health. Carrier animals excrete pathogenic Leptospira primarily in their urine. Infection occurs when the pathogen enters a host through mucosa or small skin abrasions. Humans and other animals are exposed to the pathogen by direct contact with urine, contaminated soil or water. While many factors influence environmental cycling and the transmission of Leptospira to humans, the load of pathogenic Leptospira in the environment is likely to play a major role. Peridomestic rats are often implicated as a potential source of human disease; however exposure to other animals is a risk factor as well. The aim of this report is to highlight the importance of various carrier animals in terms of the quantity of Leptospira shed into the environment. For this, we performed a systematic literature review and a meta-analysis of the amount of pathogen that various animal species shed in their urine.
\end{abstract}

Results: The quantity of pathogen has been reported for cows, deer, dogs, humans, mice, and rats, in a total of 14 research articles. We estimated the average Leptospira per unit volume shed by each animal species, and the daily environmental contribution by considering the total volume of urine excreted by each carrier animal. Rats excrete the highest quantity of Leptospira per millilitre of urine (median $=5.7 \times 10^{6}$ cells), but large mammals excrete much more urine and thus shed significantly more Leptospira per day $\left(5.1 \times 10^{8}\right.$ to $1.3 \times 10^{9}$ cells $)$.

Conclusions: Here we illustrate how, in a low-income rural Ecuadorian community, host population demographics, and prevalence of Leptospira infection can be integrated with estimates of shed Leptospira to suggest that peridomestic cattle may be more important than rats in environmental cycling and ultimately, transmission to humans.

Keywords: Leptospira, Animal reservoirs, Urine, Transmission

\section{Background}

Leptospirosis is a zoonotic disease caused by spirochete bacteria in the genus Leptospira. Early stages of human leptospirosis are characterized by non-specific symptoms such as headaches, high fever, jaundice, and mucosal hemorrhages; severe disease may produce multisystem complications such as acute renal or hepatic failure, or severe pulmonary hemorrhaging among other

\footnotetext{
*Correspondence: talima.pearson@nau.edu

1 Pathogen \& Microbiome Institute, Northern Arizona University, Flagstaff, AZ 86011-4073, USA

Full list of author information is available at the end of the article
}

pathologies [1]. A variety of animals including rats, horses, cattle, dogs, pigs [2-5], and numerous wild life species such as bats, coyotes, raccoons, sea lions, opossums, coyotes, white-tailed deer and even frogs and caimans [6-11] have also been shown to carry pathogenic Leptospira. Upon infection, Leptospira bacteria become particularly concentrated in the kidneys and genital tracts [12] where they can be shed into the environment via urine. As such, any infected human or animal can potentially infect others directly or indirectly by contaminating the environment. Outside a host, pathogenic Leptospira can survive in soil and water $[13,14]$. Transmission can 
occur when contaminated urine, soil, or water comes into contact with exposed mucosa, wounded skin or when ingested $[14,15]$.

Human and animal leptospirosis outbreaks are most commonly reported in tropical rural and urban slums [1, 16-18], however they also occur in cities throughout the world [18-21]. In urban areas, where most studies have been conducted [15], rats and dogs are common and have often been identified as potential sources of human infection [1, 2, 5, 14, 22-25]. Contact with other animals, such as livestock, is commonly regarded as an occupational, rather than peridomestic risk factor [26, 27]. However, in rural areas, contact with a variety of animals and livestock can be more common and therefore not restricted to occupational exposure $[28,29]$. In many agrarian and pastoralist communities, families live in close proximity to their animals, increasing the likelihood of peridomestic contact for all family members. In tropical developing countries, up to $65 \%$ of humans live in rural areas [30], and despite the likely importance of a diverse array of potential animal hosts and the impact of the environment, the role of rats is perhaps overrepresented in the peer-reviewed and public health literature.

Our aim here is to provide a focused meta-analysis to explore the potential importance of a variety of animals in shedding Leptospira into the environment. In doing this, we focus on species-specific estimates of the amount of Leptospira shed in urine. To illustrate the potential load of Leptospira shed into the environment via cattle urine, we combined prevalence and demographic data from a highly endemic rural community in Ecuador with quantitative shedding estimates from individual animals. We thus discuss the importance of host densities in determining the overall quantity of Leptospira shed into the environment. Given the paucity of data on many animals, our analysis is restricted to a small number of peridomestic species and one wild species. The role of different animals in the environmental cycling of these pathogens is likely regionally and culturally specific and may be impacted by the dynamic nature of Leptospira strain or species prevalence. However, knowledge of the potential roles of a variety of animals is essential for estimating risks posed by different host species towards a better understanding of conditions under which disease or outbreaks are most likely.

\section{Methods}

\section{Quantifying shed Leptospira}

We searched Pubmed (http://www.ncbi.nlm.nih.gov/ pubmed) and Web of Science (http://apps.webofknowledge.com) on October 24th, 2015 using the terms "Leptospira AND ((Shedding) OR (Excretion) OR (Leptospiruria))" without restrictions on publication date. We retrieved 110 titles from Web of Science and 125 from Pubmed. Removing duplicates left 156 total. By screening abstracts, we excluded 126 papers that were not about leptospirosis, did not quantify Leptospira in urine, or were in languages other than English or Spanish. We further screened the 30 remaining papers to include only 14 that reported the quantity of Leptospira in urine of animals infected naturally or experimentally (Additional file 1: Figure S1). Quantity of shed Leptospira per millilitre by animal type was either extracted from manuscript figures using WebPlot Digitizer [31] or from manuscript tables. Quantity shed by dogs was kindly provided by Jarlath Nally and Pablo Rojas [32]. For each manuscript, we recorded characteristics of the quantification method: target gene, lowest limit of detection (ILoD), and Leptospira clade [17] specificity of assays (Table 1). Leptospira load per millilitre of urine was registered for each animal type (Additional file 2: Table S1).

\section{Host comparisons}

We performed a Kruskal-Wallis test [33] to assess differences in the quantity of Leptospira shed among animal species (cattle, deer, dogs, humans, rats, and mice). To test whether the quantification method (qPCR-quantitative PCR, scanning laser densitometry, gel quantification, or dark field microscopy enumerations) caused differences in the mean Leptospira quantity, we compared results from within a host species across quantification methods using the Wilcoxon Rank Sum Test [34]. Leptospira load per millilitre of urine were transformed to Log base 10 for data analysis. Average volume of urine shed per animal was calculated from the literature: cattle [35], deer [36], dogs [37], humans [38], mice [39], and rats [40] (Additional file 3: Table S2).

\section{Estimation of Leptospira quantity shed by cattle in an endemic rural community}

In a previous study [41] we found that $35.4 \%$ of cows living in Abdon Calderon Parish in Manabi province (Ecuador) were shedding Leptospira DNA in their urine. The Ecuadorian Ministry of Agriculture conducted the most recent census in 2000 (http://sinagap.agricultura.gob.ec/ censo-nacional-agropecuario). Data from this census, contained in the Ministerio de Agricultura, Ganaderia, Acuacultura y Pesca (MAGAP) database [42], showed a total of 78 properties in Abdon Calderon with a total of 886 cattle. We calculated the contribution of Leptospira from cattle by modifying the formula used by Costa et al. [5]: DPC $=$ PS $^{*}$ Prev $*$ Vol*Load, where DPC = Daily population contribution, PS = Population size (number of cattle per property size; $0.35-1,1-5,5-10$ ha, and more than 10 ha), Prev = prevalence in the given population (35.4\%), $\mathrm{Vol}=$ is the average volume of urine shed per 
day, and load is defined as $\log$ of cell/ $/ \mathrm{mL}$. Given that the average volume of urine shed per urination event is $2 \mathrm{~L}$ [35] and the average number of urination events per day is 7-12 [43, 44], we calculated $\mathrm{Vol}=16 \mathrm{~L}$.

\section{Results}

\section{Quantity of Leptospira shed in urine}

We identified fourteen articles that quantified pathogenic Leptospira in urine from experimentally or naturally infected animals. Quantification methods included dark-field microcopy, scanning laser densitometry, gel electrophoresis, and qPCR (Additional file 2: Table S1). Five different qPCR assays have been used to quantify Leptospira in urine of experimental or naturally infected animals (Table 1). Four of five qPCR assays target only species that belong in the pathogenic clade while one assay also detected infectious Leptospira from the "intermediate" clade. We found no significant differences in quantification methods among studies of cattle $(\mathrm{W}=16$, $\mathrm{p}=0.095)$ and rats $(\mathrm{W}=107, \mathrm{p}=0.238)$.

Shed Leptospira have been quantified for cattle, deer, dogs, humans, mice and rats (Table 1; Additional file 2: Table S1). The quantity of pathogenic Leptospira shed per millilitre of animal urine differs significantly by species (Fig. 1a; Additional file 4: Table S3). The lowest quantity of Leptospira shed per millilitre of urine was calculated for humans (32 cells $/ \mathrm{mL}$ ) while the highest quantity was calculated for rats $\left(8 \times 10^{8}\right.$ cells $\left./ \mathrm{mL}\right)$. When estimating median absolute quantity of Leptospira shed per day, mice shed the least $\left(1.9 \times 10^{5}\right.$ cells $)$, and cattle and deer the highest with $6.3 \times 10^{8}$ and $6.1 \times 10^{8}$ cells, respectively (Additional file 4: Table S3).

\section{Daily population contribution of pathogenic Leptospira via cattle urine in an endemic rural community}

The estimated daily quantity of pathogenic Leptospira shed by cattle in Abdon Calderon (Ecuador) was calculated using the local prevalence in cattle of $35.4 \%$ [41], demographic data collected by MAGAP [42], and daily quantity (median) of Leptospira shed by cattle (Additional file 4: Table S3). Grazing range characteristics are likely to play a role in the concentration of environmental Leptospira as well as the likelihood of direct or indirect contact of contaminated urine by humans. Some properties in this area are fenced and others are not, but such information was not registered in the census database, limiting our ability to make inferences about interactions of animals across properties or with wildlife. In Abdon Calderon, the lowest estimate $\left(4.9 \times 10^{3}\right.$ cells $/ \mathrm{m}^{2} /$ day $)$ of the amount of pathogenic Leptospira shed via cattle urine was associated with the lowest estimated density of cattle ( 1 animal in 4.2 ha). Conversely, given that some herds with as many as 40 cattle were confined to a grazing area of only 2 ha, we estimated the amount of pathogenic Leptospira shed via urine per day to be $4.2 \times 10^{5}$ cells/ $\mathrm{m}^{2} /$ day. Importantly, 91 cattle at the study site live on properties without grazing areas (Table 2). These cattle are therefore moved through the community to drink and graze but are likely to spend much of their time confined to a very small area. These cattle may be shedding approximately $1.96 \times 10^{10}$ cell/day, however we cannot estimate the area that they may contaminate.

\section{Discussion}

A wide variety of animals can be infected with leptospira and might transmit the pathogen to humans, however the relative roles of each animal species is not well understood. Given the role of urine in seeding the environment with Leptospira, we illustrate how animal physiology and population data can be used to estimate the environmental load of the pathogen. Rats are traditionally thought to be the main reservoir for human transmission even though a variety of animals have also been implicated. Our results show that while rats may excrete the highest concentration of pathogen, the concentration, coupled with volume and animal density will dictate the total

Table 1 Techniques used to measure quantity of Leptospira in urine

\begin{tabular}{|c|c|c|c|c|}
\hline Target Gene & Leptospira clade ${ }^{a}$ & Method & ILoD $^{\mathbf{b}}$ & Reference \\
\hline- & All Leptospira species & Darkfield microscopy & Semiquantitative & Nally et al. [45]; Monahan et al. [46] \\
\hline Non identified & Pathogenic clade & Conventional PCR & Semiquantitative & Gerritsen et al. $[47,48]$ \\
\hline- & Pathogenic clade & Slot blot -Scanning laser densitometry & Semiquantitative & Zuerner et al. [49] \\
\hline $165 r r n a$ & $\begin{array}{l}\text { Pathogenic clade } \\
\text { Intermediate clade }\end{array}$ & TaqMan PCR & 10 cells/mL of urine & Smyth et al. $[50,51]$ \\
\hline lip/32 & Pathogenic clade & TaqMan PCR & $10^{1}$ to $10^{2}$ cells $/ \mathrm{mL}$ of urine & Sttodard et al. [52] \\
\hline lip/32 & Pathogenic clade & TaqMan PCR & 3GEq/4.5 $\mu \mathrm{L}$ of extracted DNA & Rojas et al. [32] \\
\hline lip/32 & Pathogenic clade & TaqMan PCR & $6 \mathrm{Geq} / 5 \mu \mathrm{L}$ of extracted DNA & Villumsen et al. [53] \\
\hline gyrB & Pathogenic clade & SYTO9 PCR & $10^{3}$ cells $/ \mathrm{mL}$ & Subharat et al. [54] \\
\hline
\end{tabular}

a Leptospira species or clade as designated according to Levett [17]

b Lowest limit of detection as reported by authors 

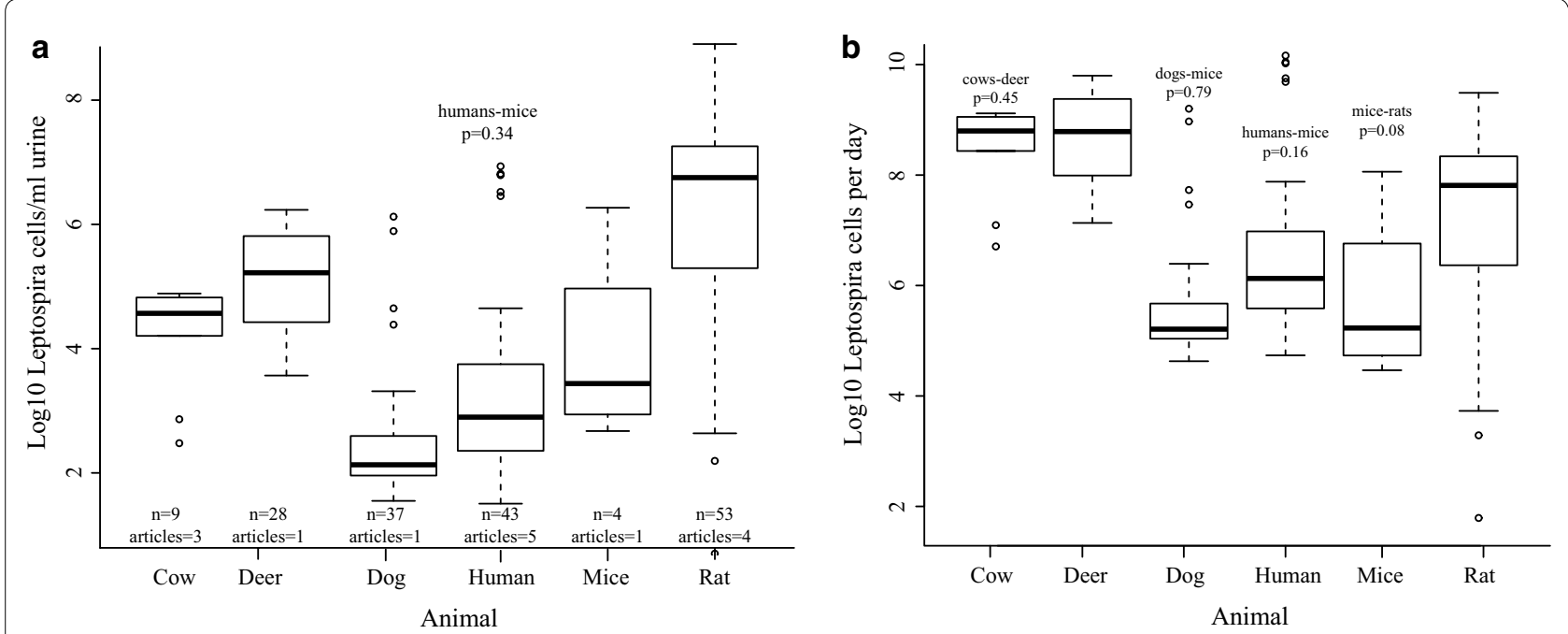

Fig. 1 Quantity of Leptospira shed by animals. a Quantity of shed Leptospira per milliliter (Log10) of urine is significantly different among animals (Kruskal-Wallis Chi squared $=96.33, p$ value $<2.2 \times 10-16$ ). Comparisons of quantity of Leptospira shed between pairs of animals were all significantly different except humans and mice (Kruskal-Wallis Chi squared $=0.91, p=0.34$ ). $\mathbf{b}$ Estimates of absolute quantity of Leptospira shed per day differ significantly among animals (Kruskal-Wallis Chi squared $=73.6, p=1.806 \times 10-14$ ). Quantity of Leptospira shed per day by cattle and deer are significantly higher than dogs, humans, mice and rats (Kruskal-Wallis Chi squared $=45.6, p=1.45 \times 10-11$ ). No significant differences were found when comparing cattle and deer, dogs and mice, humans and mice, and rats and mice. Box-plots display the medians, interquartile range (IQR), $1.5 \times \mathrm{IQR}$, and suspected outliers $>1.5 \times \mathrm{IQR}$

Table 2 Daily population contribution of Leptospira (DPC) by cattle herds in Abdon Calderon, Manabi, Ecuador

\begin{tabular}{lccc}
\hline Grazing area & Number of properties & $\begin{array}{l}\text { Number of cattle } \\
\text { Total (Min-Max) }\end{array}$ & $\begin{array}{l}\text { Quantity of Leptospira shed per } \mathbf{m}^{\mathbf{2}} \\
\text { Total (Min-Max) }\end{array}$ \\
\hline No grazing area & 18 & $91(1-20)$ & $1.96 \times 10^{10} \mathrm{cell} /$ day \\
0.35 to 1 ha & 9 & $26(2-5)$ & $4.2 \times 10^{4}$ to $1.5 \times 10^{5}$ \\
$>1$ to 5 ha & 30 & $219(1-40)$ & $4.9 \times 10^{3}$ to $4.2 \times 10^{5}$ \\
$>5$ to 10 ha & 10 & $176(2-70)$ & $5.9 \times 10^{3}$ to $1.5 \times 10^{5}$ \\
More than 10 ha & 10 & $354(12-80)$ & $9.2 \times 10^{3}$ to $4 \times 10^{4}$ \\
\hline
\end{tabular}

amount of pathogen in the environment. Our results illustrate how larger host species may play an important role in leptospirosis transmission and should not be overlooked.

Urine is the primary avenue for shedding Leptospira and thus plays a central role in the environmental cycling of this pathogen and infection risk [2]. Contact with contaminated urine, either directly or indirectly through contaminated soil or water can lead to transmission [14]. Many animals have been documented as competent hosts to Leptospira, but it is likely that these animals represent only a fraction of likely hosts that may play important roles in the environmental cycling and epidemiology of Leptospira. While contact with cattle and other livestock has been associated with transmission to humans, this interaction is mostly treated as an occupational risk, given that many studies were conducted in rural and urban slums where non-occupational animal contact mostly involves peridomestic rats and dogs. In many human populations, however, interactions within a diverse group of wildlife are common. Our aim here was to explore the potential roles of a variety of animals in Leptospira eco-epidemiology, illustrate how animal population data can be used to estimate the environmental load of Leptospira, and discuss other variables that may contribute to the likelihood of human infection.

We identified 14 research articles that quantified the amount of Leptospira shed in urine. These works were limited to six species and employed a number of different methods. As multiple articles employed different methods for quantifying Leptospira in urine from rats and cattle, we were able to determine that these different methods did not result in significant differences. Molecular methods may over-estimate quantity of Leptospira 
excreted in urine as they detect alive and dead bacteria, however microscopy quantification, detecting live cells shed by rats are within the range detected by qPCR, suggesting that the quantity of dead cells may not be significant. Furthermore, there is no evidence that this will affect relevant comparisons across species as performed in this meta-analysis. Among other variables, the absolute quantity of Leptospira shed per day by an infected animal depends on the quantity of pathogen in urine as well as the total daily volume of excreted urine. While rats may shed more Leptospira per unit volume of urine, the small overall volume of excreted urine limits their overall contribution to the environmental load. Larger animals such as cattle and deer shed less Leptospira per unit volume of urine, however the sheer volume of urine excreted by such animals can result in a significantly higher environmental contribution compared to rats and other animals. In some environments, however, extremely high rat densities will drastically increase the amount of urine shed into the environment. Therefore, in order to determine the overall contribution of an individual host species, population density and prevalence must also be considered.

There is little information on the prevalence of Leptospira in a given host species [55], and prevalence is likely to vary across regions and seasons $[15,56]$. In 20142015, we estimated Leptospira prevalence among cattle (35.4\%), pigs (5.7\%), and rats (2.8\%) in Abdon Calderon, Ecuador [41]. Demographic data on cattle ownership were not collected for this time period and the most recent data were collected in 2000 . Undoubtedly population sizes have changed, however these data illustrate how demographic and prevalence data can be used to estimate the daily load of Leptospira shed per unit area. Given the availability of host population and leptospirosis prevalence data, models should ideally include multiple host species, including humans.

Animal behavior and animal husbandry practices will influence the load and distribution of pathogens shed into the environment as well as the likelihood of transmission to humans. Animal density will affect environmental load and our consideration of grazing area only provides a rough illustration of how shed Leptospira may be distributed. Cattle are gregarious, and even when provided a large grazing area, may spend a large portion of their time concentrated in small areas associated with bedding, feeding and watering, resulting in uneven distribution of shed Leptospira. Animal husbandry practices may increase the likelihood of human contact with shed Leptospira. Many cattle owners (23\%) in Abdon Calderon do not own property on which to graze their herd. These animals (10.5\% of the total cattle population) graze in public areas and are thus not segregated from the general human population. Also, these animals will spend significant amounts of time in the small peridomestic environment, increasing contact with family members, and presenting a non-occupational risk of infection. Similarly, humans may be more likely to come into contact with Leptospira shed from other humans. Human prevalence rates may be underestimated if only symptomatic patients are considered, and an infected human may shed $1.3 \times 10^{6}$ cells per day. Human shedding may not play a significant role in the environmental cycling and transmission of Leptospira in places with good sewage infrastructure and available toilet facilities, however such infrastructure is lacking in most of the world. More complex modeling of Leptospira shedding must incorporate higher-resolution estimations of distributional variation and how shed Leptospira may come into contact with other animals and ultimately, humans.

Climatic variation is likely to result in temporal changes in leptospirosis prevalence among humans $[13,57]$ and other animals. Climate and weather can impact host population sizes, distribution, behaviors, and interactions. Environmental conditions can also affect survivorship and environment distribution of shed Leptospira. Indeed, Leptospira have been shown to survive best in soil with high relative humidity and neutral $\mathrm{pH}[58,59]$. Flooding and heavy rainfall have been associated with some leptospirosis outbreaks, but even during droughts, stagnant water or ponds may serve as refugia for Leptospira [60-62]. In Abdon Calderon across 2014-2015, recorded flooding events were rare and the local Health Ministry authorities reported isolated leptospirosis cases and no outbreaks. Flooding may serve as the main mechanism for distribution of shed Leptospira, providing a means for contacting Leptospira shed from animals that may not typically be transmitted between certain host species.

Lastly, the high genetic heterogeneity among Leptospira has resulted in variation in virulence and a certain degree of host adaptation [2]. It is also likely that certain species or genotypes may have differential environmental survivorship. Fourteen out of 21 Leptospira species cause disease, and within them, more than 200 serovars have been described [17]. Knowledge of circulating genotypes must certainly play a role in epidemiological modeling of Leptospira.

\section{Conclusion}

We have focused this illustration on cattle; population, infection prevalence, and the quantity of Leptospira shed for many species are not available, and the high prevalence and high estimated daily shedding suggests that cattle in Abdon Calderon may have been the most important source of Leptospira in 2014-2015. However, more thorough modeling of environmental loads and the 
likelihood of direct/indirect human contact with urine must consider multiple host species, host behavior or animal husbandry practices that increase the likelihood of transmission to humans or other animals, and circulating pathogen genotypes that may differentially impact host species. To our knowledge, there are no reports that directly link an infected animal to a human leptospirosis case. Therefore, epidemiological investigations coupled with genotyping data of the pathogen will provide valuable insights into the roles of different animals in leptospirosis transmission and will confirm or refute our hypothesis of the importance of urine volume for Leptospira load in the environment and risk for human health.

\section{Additional files}

Additional file 1: Figure S1. Study flow diagram.

Additional file 2: Table S1. Leptospira quantity data extracted from the articles analyzed in this meta-analysis.

Additional file 3: Table S2. Urine volume excreted by animals. Additional file 4: Table S3. Estimated quantity of Leptospira shed by animals.

\section{Abbreviations}

ILoD: lowest limit of detection; qPCR: quantitative PCR; MAGAP: Ministerio de Agricultura, Ganaderia, Acuacultura y Pesca; DPC: daily population contribution; PS: population size; Prev: prevalence in the given population; Vol: the average volume of urine shed per day; IQR: interquartile range.

\section{Authors' contributions}

Acquisition of data: VB. Analysis and interpretation of data: VB, NN, PK, TP. Wrote the paper:VB, TP. All authors read and approved the final manuscript.

\section{Author details}

1 Pathogen \& Microbiome Institute, Northern Arizona University, Flagstaff, AZ 86011-4073, USA. ${ }^{2}$ Department of Biological Sciences, Northern Arizona University, Flagstaff, AZ 86011-5640, USA. ${ }^{3}$ Instituto de Microbiologia, Colegio de Ciencias Biologicas y Ambientales, Universidad San Francisco de Quito, Quito, Ecuador.

\section{Acknowledgements}

We thank Drs. Jarlath Nally and Pablo Rojas for providing details on quantity of Leptospira shed in dog urine.

\section{Competing interests}

The authors declare that they have no competing interests.

\section{Availability of data and material}

All data are contained within this manuscript and supplemental materials.

\section{Funding}

This research was funded by National Institutes of Health, Award Number R15Al101913; A SENESCYT scholarship from the Ecuadorian Government; Cowden Endowment at Northern Arizona University; Universidad San Francisco de Quito.

Received: 18 May 2016 Accepted: 10 January 2017

Published online: 28 January 2017
References

1. Bharti AR, Nally JE, Ricaldi JN, Matthias MA, Diaz MM, Lovett MA, et al. Leptospirosis: a zoonotic disease of global importance. Lancet Infect Dis. 2003;3(12):757-71.

2. Levett PN. Leptospirosis. Clin Microbiol Rev. 2001;14(2):296-326. doi:10.1128/CMR.14.2.296-326.2001.

3. Ellis WA. Animal leptospirosis. Curr Top Microbiol Immunol. 2015;387:99137. doi:10.1007/978-3-662-45059-8_6.

4. Goldstein RE. Canine leptospirosis. Vet Clin North Am Small Animal Pract. 2010;40(6):1091-101. doi:10.1016/j.cvsm.2010.07.008.

5. Costa F, Wunder EA, De Oliveira D, Bisht V, Rodrigues G, Reis MG, et al. Patterns in Leptospira shedding in Norway rats (Rattus norvegicus) from Brazilian slum communities at high risk of disease transmission. PLoS Negl Trop Dis. 2015;9(6):e0003819. doi:10.1371/journal. pntd.0003819.

6. Grinder M, Krausman PR. Morbidity-mortality factors and survival of an urban coyote population in Arizona. J Wild Dis. 2001;37(2):312-7. doi:10.7589/0090-3558-37.2.312.

7. New JC Jr, Wathen WG, Dlutkowski S. Prevalence of Leptospira antibodies in white-tailed deer, Cades Cove, Great Smoky Mountains National Park, Tennessee, USA. JWildl Dis. 1993;29(4):561-7. doi:10.7589/0090-3558-29.4.561.

8. Bessa TA, Spichler A, Chapola EG, Husch AC, de Almeida MF, Sodre MM, et al. The contribution of bats to leptospirosis transmission in Sao Paulo City, Brazil. Am J Trop Med Hyg. 2010;82(2):315-7. doi:10.4269/ ajtmh.2010.09-0227.

9. Diesch SL, McCulloch WF, Braun JL, Ellinghausen HC Jr. Leptospires isolated from frog kidneys. Nature. 1966;209(5026):939-40.

10. Norman SA, DiGiacomo RF, Gulland FM, Meschke JS, Lowry MS. Risk factors for an outbreak of leptospirosis in California sea lions (Zalophus californianus) in California, 2004. J Wild Dis. 2008;44(4):837-44. doi:10.7589/0090-3558-44.4.837.

11. Rossetti CA, Uhart M, Romero GN, Prado W. Detection of leptospiral antibodies in caimans from the Argentinian Chaco. Vet Rec. 2003;153(20):632-3.

12. William E. Animal leptospirosis. In: Adler B, editor. Leptospira and leptospirosis. Berlin: Springer; 2014. p. 99-125.

13. Lau CL, Smythe LD, Craig SB, Weinstein P. Climate change, flooding, urbanisation and leptospirosis: fuelling the fire? Trans R Soc Trop Med Hyg. 2010;104(10):631-8. doi:10.1016/j.trstmh.2010.07.002.

14. Haake DA, Levett PN. Leptospirosis in humans. Curr Top Microbiol Immunol. 2015;387:65-97. doi:10.1007/978-3-662-45059-8_5.

15. Costa F, Hagan JE, Calcagno J, Kane M, Torgerson P, Martinez-Silveira MS, et al. Global morbidity and mortality of leptospirosis: a systematic review. PLoS Negl Trop Dis. 2015;9(9):e0003898. doi:10.1371/journal. pntd.0003898.

16. Ko Al, Galvao Reis M, Johnson WD Jr., Riley LW, Urban epidemic of severe leptospirosis in Brazil. Salvador Leptospirosis Study Group. Lancet. 1999;354(9181):820-5.

17. Levett PN. Systematics of leptospiraceae. Curr Top Microbiol Immunol. 2015;387:11-20. doi:10.1007/978-3-662-45059-8_2.

18. Ganoza CA, Matthias MA, Collins-Richards D, Brouwer KC, Cunningham $C B$, Segura ER, et al. Determining risk for severe leptospirosis by molecular analysis of environmental surface waters for pathogenic Leptospira. PLoS Med. 2006;3(8):e308. doi:10.1371/journal.pmed.0030308.

19. Ayral F, Zilber AL, Bicout DJ, Kodjo A, Artois M, Djelouadji Z. Distribution of Leptospira interrogans by multispacer sequence typing in urban Norway rats (Rattus norvegicus): a survey in France in 2011-2013. PLoS ONE. 2015;10(10):e0139604. doi:10.1371/journal.pone.0139604.

20. Childs JE, McLafferty SL, Sadek R, Miller GL, Khan AS, DuPree ER, et al. Epidemiology of rodent bites and prediction of rat infestation in New York City. Am J Epidemiol. 1998;148(1):78-87.

21. Firth C, Bhat M, Firth MA, Williams SH, Frye MJ, Simmonds P, et al. Detection of zoonotic pathogens and characterization of novel viruses carried by commensal Rattus norvegicus in New York City. mBio. 2014:5(5):e01933-14. doi:10.1128/mBio.01933-14.

22. Socolovschi C, Angelakis E, Renvoise A, Fournier PE, Marie JL, Davoust $B$, et al. Strikes, flooding, rats, and leptospirosis in Marseille, France. Int J Infect Dis. 2011;15(10):e710-5. doi:10.1016/j.jiji.2011.05.017. 
23. de Faria MT, Calderwood MS, Athanazio DA, McBride AJA, Hartskeerl RA, Pereira MM, et al. Carriage of Leptospira interrogans among domestic rats from an urban setting highly endemic for leptospirosis in Brazil. Acta Trop. 2008;108(1):1-5. doi:10.1016/j.actatropica.2008.07.005.

24. Azocar-Aedo L, Monti G. Meta-analyses of factors associated with Leptospirosis in domestic dogs. Zoonoses Public Health. 2015. doi:10.1111/ zph.12236.

25. Munoz-Zanzi C, Mason M, Encina C, Gonzalez M, Berg S. Household characteristics associated with rodent presence and Leptospira infection in rural and urban communities from Southern Chile. Am J Trop Med Hyg. 2014:90(3):497-506. doi:10.4269/ajtmh.13-0334.

26. Steneroden KK, Hill AE, Salman MD. Zoonotic disease awareness in animal shelter workers and volunteers and the effect of training. Zoonoses Public Health. 2011;58(7):449-53. doi:10.1111/j.1863-2378.2011.01389.x.

27. Thornley CN, Baker MG, Weinstein P, Maas EW. Changing epidemiology of human leptospirosis in New Zealand. Epidemiol Infect. 2002;128(1):29-36.

28. Agampodi SB, Nugegoda DB, Thevanesam V, Vinetz JM. Characteristics of rural leptospirosis patients admitted to referral hospitals during the 2008 leptospirosis outbreak in Sri Lanka: implications for developing public health control measures. Am J Trop Med Hyg. 2015;92(1):139-44. doi:10.4269/ajtmh.14-0465.

29. Gamage CD, Koizumi N, Muto M, Nwafor-Okoli C, Kurukurusuriya S, Rajapakse JR, et al. Prevalence and carrier status of leptospirosis in smallholder dairy cattle and peridomestic rodents in Kandy, Sri Lanka. Vector Borne Zoonotic Dis. 2011;11(8):1041-7. doi:10.1089/vbz.2010.0153.

30. Williams JN. Humans and biodiversity: population and demographic trends in the hotspots. Popul Environ. 2013;34(4):510-23. doi:10.1007/ s11111-012-0175-3

31. Rohatgi A. WebPlotDigitizer. Ankit Rohatgi. 2015. http://arohatgi.info/ WebPlotDigitizer. Accessed Oct 2015.

32. Rojas P, Monahan AM, Schuller S, Miller IS, Markey BK, Nally JE. Detection and quantification of leptospires in urine of dogs: a maintenance host for the zoonotic disease leptospirosis. Eur J Clin Microbiol Infect Dis. 2010;29(10):1305-9. doi:10.1007/s10096-010-0991-2.

33. William $\mathrm{H}$, Kruskal WAW. Use of ranks in one-criterion variance analysis. J Am Stat Assoc. 1952;47(260):583-621.

34. Frank W. Individual comparisons by ranking methods. Biom Bull. 1945;1(6):80-3.

35. Moir JL, Cameron KC, Di HJ, Fertsak U. The spatial coverage of dairy cattle urine patches in an intensively grazed pasture system. J Agr Sci. 2011;149:473-85. doi:10.1017/S0021859610001012.

36. Maloiy GM, Scott D. Renal excretion of urea and electrolytes in sheep and red deer. J Physiol. 1969;205(1):91-101

37. William R. Kidney function in mammals. In: Reece W, editor. Dukes physiology of domestic animals. Ithaca: Cornell University Press; 2004. p 73-106.

38. Armstrong LE, Johnson EC, McKenzie AL, Munoz CX. An empirical method to determine inadequacy of dietary water. Nutrition. 2015. doi:10.1016/j.nut.2015.07.013.

39. Stechman MJ, Ahmad BN, Loh NY, Reed AA, Stewart M, Wells S, et al. Establishing normal plasma and 24-hour urinary biochemistry ranges in $\mathrm{C} 3 \mathrm{H}, \mathrm{BALB} / \mathrm{C}$ and $\mathrm{C} 57 \mathrm{BL} / 6 \mathrm{~J}$ mice following acclimatization in metabolic cages. Lab Animal. 2010:44(3):218-25. doi:10.1258/la.2010.009128.

40. Donaldson $\mathrm{HH}$. The rat. Reference tables and data for the albino rat (Mus norvegicus albinus) and the Norway rat (Mus norvegicus). Philadelphia 1915. http://www.biodiversitylibrary.org/item/62983.

41. Barragan V, Chiriboga J, Miller E, Olivas S, Birdsell D, Hepp C, Hornstra H, Schupp JM, Morales M, Gonzalez M, Reyes S, de la Cruz C, Keim P, Hartskeerl R, Trueba G, Pearson T. High leptospira diversity in animals and humans complicates the search for common reservoirs of human disease in rural Ecuador. PLoS Negl Trop Dis. 2016;10(9):e0004990. doi:10.1371/ journal.pntd.0004990.

42. Ministerio de Agricultura G, Acuacultura y Pesca (MAGAP) III CENSO NACIONAL AGROPECUARIO. In: Sistema de Información Nacional de Agricultura G, Acuacultura y Pesca-SINAGAP, editor. http://sinagap.agricultura. gob.ec/censo-nacional-agropecuario2000.

43. Aland A, Lidfors L, Ekesbo I. Diurnal distribution of dairy cow defecation and urination. Appl Anim Behav Sci. 2002;78(1):43-54. doi:10.1016/ S0168-1591(02)00080-1.
44. Oudshoorn FW, Kristensen T, Nadimi ES. Dairy cow defecation and urination frequency and spatial distribution in relation to time-limited grazing. Livest Sci. 2008;113(1):62-73. doi:10.1016/j.livsci.2007.02.021.

45. Nally JE, Monahan AM, Miller IS, Bonilla-Santiago R, Souda P, Whitelegge JP. Comparative proteomic analysis of differentially expressed proteins in the urine of reservoir hosts of leptospirosis. PLOS ONE. 2011;6(10):e26046. doi:10.1371/journal.pone.0026046.

46. Monahan AM, Callanan JJ, Nally JE. Proteomic analysis of Leptospira interrogans shed in urine of chronically infected hosts. Infect Immun. 2008;76(11):4952-8. doi:10.1128/IAI.00511-08.

47. Gerritsen MJ, Olyhoek T, Smits MA, Bokhout BA. Sample preparation method for polymerase chain reaction-based semiquantitative detection of Leptospira interrogans serovar hardjo subtype hardjobovis in bovine urine. J Clin Microbiol. 1991;29(12):2805-8.

48. Gerritsen MJ, Koopmans MJ, Olyhoek T. Effect of streptomycin treatment on the shedding of and the serologic responses to Leptospira interrogans serovar hardjo subtype hardjobovis in experimentally infected cows. Vet Microbiol. 1993:38(1-2):129-35.

49. Zuerner RL, Bolin CA. Repetitive sequence element cloned from Leptospira interrogans serovar hardjo type hardjo-bovis provides a sensitive diagnostic probe for bovine leptospirosis. J Clin Microbiol. 1988:26(12):2495-500.

50. Smythe LD, Smith IL, Smith GA, Dohnt MF, Symonds ML, Barnett LJ, et al. A quantitative PCR (TaqMan) assay for pathogenic Leptospira spp. BMC Infect Dis. 2002;2:13.

51. Ganoza CA, Matthias MA, Saito M, Cespedes M, Gotuzzo E, Vinetz JM. Asymptomatic renal colonization of humans in the peruvian Amazon by Leptospira. PLoS Negl Trop Dis. 2010;4(2):e612. doi:10.1371/journal. pntd.0000612.

52. Stoddard RA, Gee JE, Wilkins PP, McCaustland K, Hoffmaster AR. Detection of pathogenic Leptospira spp. through TaqMan polymerase chain reaction targeting the LipL32 gene. Diagn Microbiol Infect Dis. 2009;64(3):247-55. doi:10.1016/j.diagmicrobio.2009.03.014

53. Villumsen S, Pedersen R, Borre MB, Ahrens P, Jensen JS, Krogfelt KA. Novel TaqMan(R) PCR for detection of Leptospira species in urine and blood: pit-falls of in silico validation. J Microbiol Methods. 2012;91(1):184-90. doi:10.1016/j.mimet.2012.06.009.

54. Subharat S, Wilson PR, Heuer C, Collins-Emerson JM. Evaluation of a SYTO9 real-time polymerase chain reaction assay to detect and identify pathogenic Leptospira species in kidney tissue and urine of New Zealand farmed deer. J Vet Diagn Investig. 2011;23(4):743-52. doi:10.1177/1040638711407892.

55. Cosson JF, Picardeau M, Mielcarek M, Tatard C, Chaval Y, Suputtamongkol $Y$, et al. Epidemiology of leptospira transmitted by rodents in southeast Asia. PLoS Negl Trop Dis. 2014;8(6):e2902. doi:10.1371/journal. pntd.0002902.

56. Chiriboga J, Barragan V, Arroyo G, Sosa A, Birdsell DN, Espana K, et al. High prevalence of intermediate Leptospira spp. DNA in febrile humans from urban and rural Ecuador. Emerg Infect Dis. 2015;21(12):2141-7. doi:10.3201/eid2112.140659.

57. Watson JT, Gayer M, Connolly MA. Epidemics after natural disasters. Emerg Infect Dis. 2007;13(1):1-5. doi:10.3201/eid1301.060779.

58. Hellstrom JS, Marshall RB. Survival of Leptospira-interrogans-serovarpomona in an acidic soil under simulated New-Zealand field conditions. Res Vet Sci. 1978:25(1):29-33.

59. Saito M, Villanueva SY, Chakraborty A, Miyahara S, Segawa T, Asoh T, et al. Comparative analysis of Leptospira strains isolated from environmental soil and water in the Philippines and Japan. Appl Environ Microbiol. 2013;79(2):601-9. doi:10.1128/AEM.02728-12.

60. Jackson LA, Kaufmann AF, Adams WG, Phelps MB, Andreasen C, Langkop CW, et al. Outbreak of leptospirosis associated with swimming. Pediatr Infect Dis J. 1993:12(1):48-54

61. Crawford RP, Heinemann JM, McCulloch WF, Diesch SL. Human infections associated with waterborne Leptospires, and survival studies on serotype pomona. J Am Vet Med Assoc. 1971;159(11):1477-84.

62. Corwin A, Ryan A, Bloys W, Thomas R, Deniega B, Watts D. A waterborne outbreak of Leptospirosis among United-States military personnel in Okinawa, Japan. Int J Epidemiol. 1990;19(3):743-8. doi:10.1093/ lje/19.3.743. 